Tersedia online di

http://ojs.unik-kediri.ac.id/index.php/ukarst/index

U KaRsT http://dx.doi.org/10.30737/ukarst.v4i1

\title{
Pemanfaatan Limbah Tempurung Kelapa Sebagai Campuran Paving Block (Ditinjau Dari Kuat Tekan dan Resapan Air)
}

\author{
I A Sucahyo ${ }^{1}$, H R Agustapraja ${ }^{2}$, B Damara ${ }^{3}$ \\ ${ }^{1,2,3}$ Fakultas Teknik, Universitas Islam Lamongan. \\ email: ilhamadjisucahyo@gmail.com
}

\begin{tabular}{ll} 
A R T I C L E & I N F O \\
\hline Article history : & \\
Artikel masuk & $: 03-03-2020$ \\
Artikel revisi & $: 12-03-2020$ \\
Artikel diterima & $: 13-03-2020$ \\
\hline
\end{tabular}

Keywords :

Coconut Shell, Paving, Strength, Absorption.

Style IEEE dalam mensitasi artikel ini: [17] J.Kaufmann. (2020). Evaluation of the combination of desert sand and calcium sulfoaluminate cement for the production of concrete $l$. Constr. Build. Mater., vol.243),118 - 281. [Semen adalah bahan dalam beton yang berfungsi sebagai pengikat beton]

\begin{abstract}
A B S T R A C T
The main objective of this study was to find out and analyze how much the influence of the coconut shell charcoal had on changes in compressive strength and water absorption in the K-175 paving block. This research method is experimental research, which is a research of making paving block specimens, by conducting activities or experiments using coconut shell waste as a mixture of paving blocks, with a mix design mix referring to the comparison of concrete mix with K-175 quality (SNI 03-2834-2000). The conversion value of compressive strength of specimens at the age of 7 days to 28 days from specimens N, 5\%,10\%, 15\% and $20 \%$ is $271,80 \mathrm{~kg} / \mathrm{cm}^{2}, 205,12 \mathrm{~kg} / \mathrm{cm}^{2}, 102,57 \mathrm{~kg} / \mathrm{cm}^{2}, 76,92 \mathrm{~kg} / \mathrm{cm}^{2}$ and $64,11 \mathrm{~kg} / \mathrm{cm}^{2}$ respectively. In the normal test code, the paving block is classified as class B quality, while the 5\% specimen code is classified as class B quality, for the test object code 10\%, 15\%, and $20 \%$ do not meet the paving block quality standards. The results of the water absorption test increased in paving blocks with a combination of coconut shell charcoal. All of them have increased water infiltration on paving blocks.
\end{abstract}

\section{A B S T R A K}

Tujuan utama dari penelitian ini adalah untuk mengetahui dan menganalisa seberapa besar pengaruh arang tempurung kelapa terhadap perubahan kuat tekan dan resapan air pada paving block K-175. Metode penelitian ini adalah penelitian eksperimen, yaitu penelitian pembuatan benda uji paving block, dengan cara melakukan kegiatan atau percobaan pemanfaatan limbah tempurung kelapa sebagai campuran paving block, dengan perbandingan mix design mengacu pada perbandingan campuran beton dengan mutu K-175 (SNI 03-2834-2000). Hasil nilai konversi kuat tekan benda uji pada umur 7 hari ke umur 28 hari dari benda uji N, $5 \%, 10 \%, 15 \%$, dan $20 \%$ adalah $271,80 \mathrm{~kg} / \mathrm{cm}^{2}$, $205,12 \mathrm{~kg} / \mathrm{cm}^{2}, 102,57 \mathrm{~kg} / \mathrm{cm}^{2}, 76,92 \mathrm{~kg} / \mathrm{cm}^{2}$ dan $64,11 \mathrm{~kg} / \mathrm{cm}^{2}$. Pada kode benda uji normal paving block tergolong dalam mutu kelas B, sedangkan pada kode benda uji 5\% tergolong dalam mutu kelas B, untuk kode benda uji 10\%, 15\%, dan $20 \%$ tidak memenuhi standar mutu paving block. Hasil dari uji resapan air paving block dengan penambahan arang tempurung kelapa dari 
benda uji 5\%,10\%, 15\% dan 20\%. Kesemuanya mengalami peningkatan resapan air pada paving block.

\section{Pendahuluan}

Bata beton paving block adalah suatu komposisi bahan bangunan yang dibuat dari campuran semen portland atau bahan perekat hidrolis sejenisnya, air dan agregat dengan atau tanpa bahan tambahan lainnya yang tidak mengurangi mutu batan beton tersebut (SNI-030691-1996). [1] karena pembuatan dan bahan yang mudah didapatkan, paving block banyak dibuat oleh industri rumahan baik dengan cara konvensional maupun modern. Paving block banyak digunakan sebagai lapis perkerasan jalan, parkiran, halaman rumah dan gang-gang kecil yang berada di desa maupun perkotaan [2][3] keunggulan paving block yaitu memiliki daya serap yang baik. [4] Dengan manfaat paving block yang mampu menunjang fasilitas masyarakat maka dituntut pula kualitas paving block yang kuat dan mempunyai daya serap air serta kualitas yang baik yang sesuai dengan kriteria standar yang diperlukan [5][6]. Kualitas paving block dipengaruhi oleh campuran serta proporsi material penyusunnya. [7]

Limbah tempurung kelapa banyak dijumpai di berbagai macam tempat, seperti di pasar tradisional, industri rumahan olahan kuliner, dan tempat-tempat yang menjual untuk memenuhi kebutuhan konsumen sehari-hari, limbah tempurung kelapa belum sepenuhnya dimanfaatkan sebagai bahan yang bersifat ekonomis, bahkan sering digunakan sebagai tungku dapur atau dibiarkan menumpuk, hal itu jika dibiarkan akan menjadi polusi. [8] [9] Oleh karena itu dalam penelitian ini bertujuan untuk membuat komposisi campuran dan meningkatkan kuat tekan paving block dengan subtitusi arang tempurung kelapa dari berat pasir yang digunakan. Penelitian ini diharapkan agar menghasilkan paving block yang berkualitas, mempunyai kemampuan daya serap air yang baik dan mampu menahan beban yang lebih baik.

Dalam penelitian ini pemanfaatan limbah tempurung kelapa dari industri rumahan olahan kuliner wingko yang tidak termasuk dalam bahan olahan, yang berlokasikan di Kecamatan Widang - Kabupaten Tuban. Tempurung kelapa bagian dari buah yang berupa endokrab, bersifat keras dan tajam yang diselimuti serabut kelapa. tempurung kelapa dalam penelitian ini diolah dan di bakar sampai menjadi arang sebagai bahan substitusi agregat halus pada pembuatan paving block.

Penelitian mengenai pengaruh penambahan tempurung kelapa terhadap paving block telah dilakukan sebelumnya dengan judul riset "Pengaruh Penambahan Abu Tempurung Kelapa Terhadap Kuat Tekan Paving Block” [10] dengan prosentase 0\%, 5\%, 10\%, 15\%, 
dan $20 \%$ dari berat semen. Hasil menunjukkan bahwa penambahan tempurung kelapa 0\%, 5\%, dan 15\% memenuhi persyaratan kekuatan paving block, sedangkan dengan prosentase $20 \%$ tidak memenuhi persyaratan kekuatan paving block.

Dalam penelitian ini akan dilaksanakan penelitian mengenai pengaruh penambahan limbah tempurung kelapa dengan prosentase 0\%,5\%,10\%,15\%, dan 20\% terhadap berat pasir. Mutu paving block yang digunakan yaitu K-175. Proses pembuatan paving block dengan cara manual. Penelitian ini dilaksanakan untuk melanjutkan penelitian yang telah ada sebelumnya dengan prosentase yang sama namun dari berat pasir dan pengaruhnya terhadap kuat tekan dan resapan air.

\section{Tinjauan Pustaka}

\subsection{Paving Block.}

Paving block merupakan bahan bangunan yang terdiri dari campuran semen, agregat dan air yang mengeras dengan bentuk dan mutu yang telah ditentukan. Paving block mampu menjaga keseimbangan air tanah, serta menjadi serapan air yang baik.[11][12] Keunggulan penggunaan paving block:

1. Pelaksanaannya mudah sehingga memberikan kesempatan kerja yang luas kepada masyarakat.

2. Pemeliharaannya mudah.

3. Bila ada kerusakan, perbaikannya tidak memerlukan bahan tambahan yang banyak karena Paving block merupakan bahan yang dapat dipakai kembali meskipun telah mengalami pembongkaran.

4. Tahan terhadap beban statis, dinamik dan kejut yang tinggi.

5. Cukup fleksibel untuk mengatasi perbedaan penurunan (differential sattlement).

6. Mempunyai durabilitas yang baik.

\subsection{Klasifikasi Paving block[13] [14].}

Klasifikasi dari paving block didasarkan atas bentuk, tebal, kekuatan dan warna antara lain, yaitu :

1. Klasifikasi berdasarkan bentuk.

Secara garis besar paving block dibedakan menjadi :

- Paving block bentuk segiempat (rectangular).

- Paving block bentuk segibanyak. 


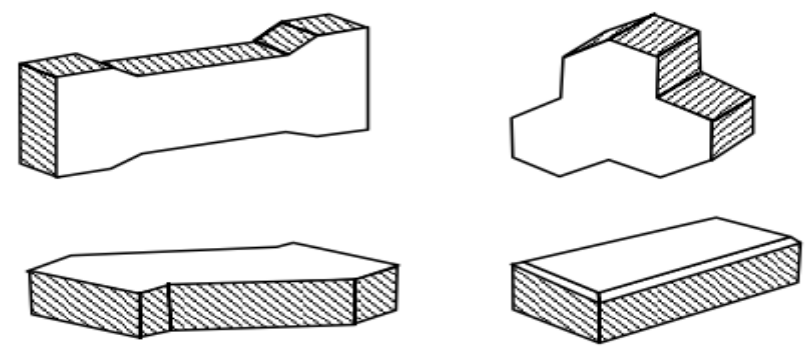

Gambar 1. Berbagai Macam Bentuk Paving block.

2. Klasifikasi berdasarkan ketebalan.

Ketebalan paving block dibedakan berdasarkan kebutuhhan dalam penggunaannya, secara umum ketebalan paving block yaitu $60 \mathrm{~mm}, 80 \mathrm{~mm}$, dan $100 \mathrm{~mm}$.

3. Klasifikasi berdasarkan kekuatan.

Kekuatan paving block berkisar antara $250 \mathrm{~kg} / \mathrm{cm}^{2}$ sampai $450 \mathrm{~kg} / \mathrm{cm}^{2}$ bergantung dari penggunaan lapis perkerasan.

4. Klasifikasi berdasarkan warna.

Warna yang digunakan pada beton dibedakan berdasarkan kebutuhan dalam penggunaannya selain menampakkan keindahan juga digunakan sebagai pembatas seperti pada tempat parkir. Warna paving block yang ada di pasaran adalah merah, hitam dan abuabu.

\section{Metode Penelitian}

Metode penelitian ini adalah penelitian eksperimen, yaitu penelitian pembuatan benda uji paving block, dengan cara melakukan kegiatan atau percobaan pemanfaatan limbah tempurung kelapa sebagai campuran paving block, yang ditinjau dari seberapa kuat tekan dan resapan air dengan mengunakan subtitusi arang tempurung kelapa dari berat pasir yang digunakan yaitu 6,910 Pc : 16,108 Ps : 0 Atk (Sebagai kode benda uji normal ). 6,910 Pc : 15,303 Ps : 0,805 Atk (Sebagai kode benda uji 5\%). 6,910 Pc : 14,497 Ps : 1,611 Atk (Sebagai kode benda uji 10\%). 6,910 Pc : 13,692 Ps : 2,416 Atk (Sebagai kode benda uji 15\%). 6,910 Pc : 12,887 Ps : 3,222 Atk (Sebagai kode benda uji 20\%).

Dalam penelitian ini pembuatan paving block dengan penambahan campuran arang tempurung kelapa dibuat benda uji sebanyak 30 buah, berbentuk persegi panjang dengan ukuran panjang $20 \mathrm{~cm}$, lebar $10 \mathrm{~cm}$ dan tebal $8 \mathrm{~cm}$. Dengan 5 (lima) variasi sampel paving block yaitu, 1 (satu) sebagai kontrol tanpa penambahan arang tempurung kelapa dan 4 (empat) diantaranya mengunakan penambahan arang tempurung kelapa sebesar 5\%, 10\%, 
15\%, 20\% dari berat pasir yang digunakan dalam pembuatan paving block. Untuk setiap variasi paving block dibuat sebanyak 6 (enam) benda uji dengan pengujian sampel, 3 (tiga) benda uji digunakan sebagai pengujian kuat tekan paving block pada umur 7 hari kemudian dikonversikan ke umur 28 hari dan 3 (tiga) diantaranya digunakan sebagai pengujian resapan air paving block pada umur 7 hari.Dalam penelitian ini perbandingan mix design mengacu pada perbandingan campuran beton dengan mutu K-175 (SNI 03-2834-2000)[15]. Perbandingan mix design paving block tanpa pengunaan agregat kasar seperti krikil dan pengunaan faktor air semen lebih sedikit yaitu sebesar 0,30 dan dengan mengunakan subtitusi arang tempurung kelapa dari berat pasir yang digunakan.

\subsection{Bahan Penyusun Paving block.}

Bahan-bahan yang digunakan dalam penelitian ini terdiri dari, semen, pasir, air, dan bahan tambah arang tempurung kelapa. Adapun bahan-bahan yang digunakan dalam pembuatan paving block sebagai berikut :

1. Semen.

Semen adalah bahan dalam beton yang berfungsi sebagai pengikat beton [16][17] semen mampu bereaksi dengan adanya air.[18] Dalam penelitian ini mengunakan semen portland type I yang banyak digunakan dalam dunia konstruksi bangunan yang diproduksi PT. Semen Gresik, dengan berat perkarungnya $40 \mathrm{~kg}$.

2. Agregat Halus.

Agregat halus berfungsi sebagai pengisi ruang antara agregat kasar sehingga menjadikan ikatan lebih kuat. [19] Agregat halus yang dipakai dalam penelitian ini adalah pasir sungai yang ada di Laboratorium Bahan Dan Teknologi Beton Jurusan Teknik Sipil, Fakultas Teknik Universitas Islam Lamongan.

3. Air.

Air mempunyai peran yang penting dalam pembuatan beton ataupun paving block. [20] Air yang digunakan dalam penelitian ini berasal dari sumber air bersih Laboratorium Bahan Dan Teknologi Beton Jurusan Teknik Sipil, Fakultas Teknik Universitas Islam Lamongan.

4. Limbah Tempurung Kelapa.

Limbah tempurung kelapa yang dipakai dalam penelitian ini diperoleh dari Home Industry olahan kuliner wingko yang berada di Kec. Widang Kab. Tuban proses pembuatan arang sebagai berikut : 
a. Limbah tempurung kelapa tersebut dibersihkan dari kotoran yang menempel dan sisasisa srabut disisihkan.

b. Masukan tempurung kelapa kedalam wadah ember besi kemudian limbah tempurung kelapa tersebut di bakar dengan api sedang.

c. Tutup atas permukaan ember besi dengan dedaunan agar proses pembakaran menghasilkan arang yang baik.

d. Sesudah pembakaran arang selesai angkat arang di wadah kemudian diangin-anginkan hingga panas pada arang hilang lalu dilakukan penumbukan menggunaka lumping untuk mendapatkan butir-butir arang yang lebih kecil.

\subsection{Lokasi Penelitian.}

Lokasi pelaksanaan penelitian maupun pengujian dilakukan di Laboratorium Bahan dan Teknologi Beton Jurusan Teknik Sipil, Fakultas Teknik, Universitas Islam Lamongan.

\subsection{Analisa Pengujian.}

Dalam melakukan metode pengujian kuat tekan dan resapan air mengunakan Acuan SNI 03-0691-1996 : paving block.

\section{Kuat Tekan}

Kuat tekan beton merupakan besarnya beban yang menyebabkan benda uji hancur bila dibebani dengan gaya tekan tertentu. [21] Untuk mengetahui besarnya nilai kuat tekan beton dapat dilakukan dengan menggunakan mesin uji tes kuat tekan beton dengan standar pengujian kuat tekan digunakan SNI. [22]

$$
K=\frac{P}{A}
$$

Dimana

$\mathrm{K}=$ Kuat tekan beton $\left(\mathrm{N} / \mathrm{mm}^{2}\right)$.

$\mathrm{P} \quad=$ Gaya tekan aksial, dinyatakan dalam newton $(\mathrm{N})$.

A = Luas penampang melintang benda uji, dinyatakan dalam $\mathrm{mm}^{2}$.

2. Penyerapan Air.

Daya serap merupakan kemampuan bahan dalam meyerap air. Kemapuan Daya serap air pada beton paving block akan mempengaruhi kualitas [23] Penyerapan air $=\frac{A-B}{B} \mathrm{X} 100$

Keterangan :
A = Berat bata beton basah.
B = Berat bata beton kering. 


\subsection{Tahapan Penelitian.}

Tahapan proses yang akan dilakukan dalam penelitian ini digambarkan dalam bagan alir pada gambar 1 sebagai berikut :

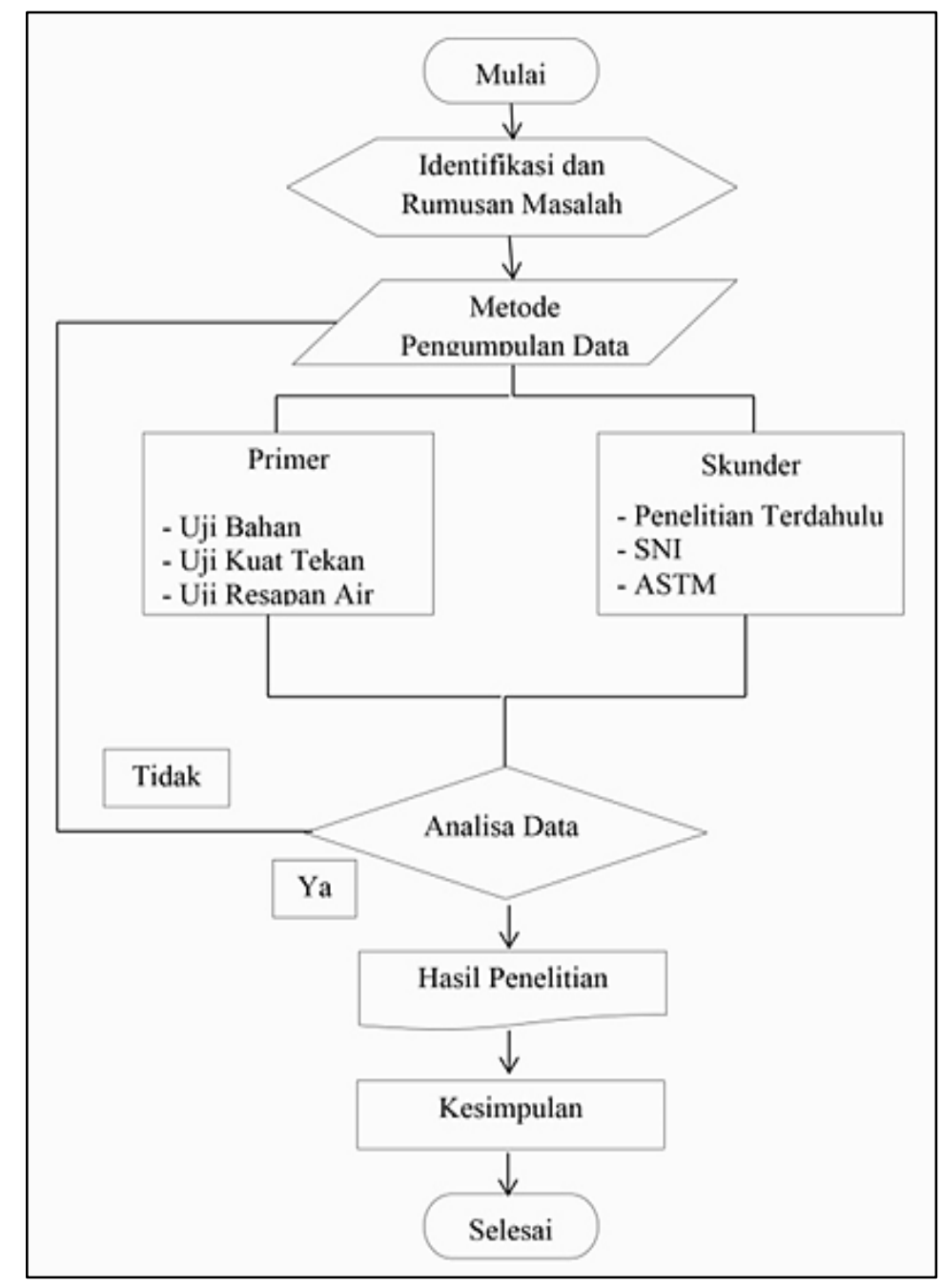

Gambar 2. Flowchart Atau Bagan Alir Penelitian.

Pada Gambar 2. menunjukkan bahwa penelitian dimulai dengan menentukan rumusan masalah yang akan dicari, setelah rumusan masalah didapat langkah selanjutnya yaitu melakukan pengumpulan meliputi data primer dan data sekunder. Data primer didapat dari hasil penelitian pengujian bahan, pengujian kuat tekan dan pengujian resapan air sedangkan data sekunder didapat dari studi literatur penelitian terdahulu, SNI dan ASTM. Setelah data didapat dilakukan anallisa data mulai dari hasil pengujian material penyusun beton, hasil pengujian slump dan hasil pengujian kuat tekan. Apabila Analisa data dianggap memenuhi dapat dijadikan sebagai hasil penelitian dan jika tidak dilakukan pengumpulan data ulang. Hasil penelitian yang didapat ditarik kesimpulan. 


\section{Hasil dan Pembahasan}

Pengujian kuat tekan dan resapan air pada umur 7 hari, pengujian dilakukan setelah proses perawatan paving block, kemudian Pengujian dilakukan untuk mengetahui kuat tekan dan resapan air benda uji dengan substitusi arang tempurung kelapa dari berat pasir yang digunakan.

\subsection{Analisa Data Kuat Tekan Paving block.}

Analisa data kuat tekan didapat dari hasil pengujian benda uji. Adapun tabel kuat tekan umur 7 hari- 28 hari sebagai berikut :

Tabel 1. Kuat Tekan Benda Uji Umur 7 hari - 28 Hari.

\begin{tabular}{ccccc}
\hline NO & $\begin{array}{c}\text { Kode } \\
\text { Benda }\end{array}$ & \multicolumn{2}{c}{$\begin{array}{c}\text { Kuat Tekan } \\
\text { Kg/cm }\end{array}$} & $\begin{array}{c}\text { Konversi } \\
\text { Satuan }\end{array}$ \\
\hline Uji & $\mathbf{7 ~ H a r i}$ & $\mathbf{2 8 ~ H a r i}$ & Ke Mpa \\
\hline $\mathbf{1}$ & N & 176.67 & 271.80 & 22.13 \\
\hline $\mathbf{2}$ & $5 \%$ & 133.33 & 205.12 & 16.70 \\
\hline $\mathbf{3}$ & $10 \%$ & 66.67 & 102.57 & 8.35 \\
\hline $\mathbf{4}$ & $15 \%$ & 50.00 & 76.92 & 6.26 \\
\hline $\mathbf{5}$ & $20 \%$ & 41.67 & 64.11 & 5.22 \\
\hline
\end{tabular}

Sumber : Data Pengujian.

Dari Tabel 1. diatas menunjukan bahwa kuat tekan paving block dengan substitusi arang tempurung kelapa dari berat pasir yang digunakan dengan prosentase 5\%, 10\%, 15\% dan 20\%, mengalami penurunan kuat tekan. Nilai kuat tekan rata-rata tertinggi diperoleh pada substitusi arang tempurung kelapa dengan kode benda uji $5 \%$ sebesar $133,33 \mathrm{~kg} / \mathrm{cm}^{2}$, sedangkan nilai terendah pada substitusi arang tempurung kelapa dengan kode benda uji $20 \%$ sebesar 41,67 kg/cm². Sedangkan paving block dengan campuran normal memperoleh nilai kuat tekan rata-rata tertinggi dari kode benda uji $5 \%$ sampai $20 \%$ sebesar $176,67 \mathrm{~kg} / \mathrm{cm}^{2}$.

Dapat dilihat dari Tabel 1. diatas nilai konversi kuat tekan benda uji pada umur 7 hari ke umur 28 hari dari benda uji N, 5\%, 10\%, 15\%, dan $20 \%$ adalah $271,80 \mathrm{~kg} / \mathrm{cm}^{2}, 205,12$ $\mathrm{kg} / \mathrm{cm}^{2}, 102,57 \mathrm{~kg} / \mathrm{cm}^{2}, 76,92 \mathrm{~kg} / \mathrm{cm}^{2}$, dan $64,11 \mathrm{~kg} / \mathrm{cm}^{2}$.

Dari Tabel 1. di atas bisa kita lihat hasil dari konversi kuat tekan $\mathrm{kg} / \mathrm{cm}^{2} \mathrm{ke} \mathrm{Mpa}$ dengan nilai berurutan dari benda uji N, 5\%,10\%, 15\% dan 20\% adalah 22,13 Mpa, 16,70 Mpa, 8,35 Mpa, 6,26 Mpa, dan 5,22. 


\subsection{Analisa Data Resapan Air Paving block}

Tabel 2. Pengujian Resapan Air Paving block

\begin{tabular}{lcccccc}
\hline No & \multicolumn{1}{c}{ Kode Benda } & Berat & Berat & $\begin{array}{c}\text { Penyerapan } \\
\text { Uji }\end{array}$ & Basah & Kenyerapan \\
& & & & Air & Rata-Rata \\
& & & $(\mathbf{K g})$ & $\mathbf{( K g )}$ & & \\
\hline $\mathbf{1}$ & $\mathrm{N}$ & 4 & 3.30 & 3.20 & 3.125 & \\
& & 5 & 3.30 & 3.20 & 3.125 & 3.13 \\
& & 6 & 3.30 & 3.20 & 3.125 & \\
\hline $\mathbf{2}$ & $5 \%$ & 4 & 2.90 & 2.80 & 3.571 & \\
& & 5 & 3.10 & 3.00 & 3.33 & 4.52 \\
& & 6 & 3.20 & 3.00 & 6.67 & \\
\hline $\mathbf{3}$ & $10 \%$ & 4 & 3.00 & 2.80 & 7.14 & \\
& & 5 & 2.70 & 2.60 & 3.85 & 6.23 \\
& & 6 & 2.80 & 2.60 & 7.69 & \\
\hline $\mathbf{4}$ & $15 \%$ & 4 & 2.60 & 2.40 & 8.33 & \\
& & 5 & 2.60 & 2.40 & 8.33 & 8.33 \\
& & 6 & 2.60 & 2.40 & 8.33 & \\
\hline $\mathbf{5}$ & $20 \%$ & 4 & 2.40 & 2.20 & 9.09 & \\
& & 5 & 2.40 & 2.20 & 9.09 & 9.09 \\
& & 6 & 2.40 & 2.20 & 9.09 & \\
\hline
\end{tabular}

Sumber : Data Pengujian.

Dari Tabel 2. di atas dapat dilihat bahwa dengan substitusi arang tempurung kelapa pada campuran dengan prosentase arang kelapa sebesar 5\%,10\%, 15\%, dan 20\% dari berat pasir yang digunakan kesemuanya mengalami peningkatan penyerapan air dari rata-rata sebesar, 4,52 pada prosentase arang kelapa 5\%, 6,23 pada prosentase arang kelapa 10\%, 8,33 pada prosentase arang kelapa $15 \%$, dan 9,09 pada prosentase arang kelapa $20 \%$.

Pembahasan dalam penelitian ini adalah menganalisa hasil pengujian kuat tekan dan resapan air pada pembuatan paving block dengan penambahan arang tempurung kelapa dari pengurangan berat pasir yang digunakan. Dalam penelitian ini untuk mengetahui seberapa pengaruh kuat tekan dan resapan air dengan mengunakan arang tempurung kelapa dari pengurangan agregat halus yang digunakan. Adapun hasil pengujian kuat tekan dan resapan air paving block dengan mengunakan bahan tambah arang tempurung kelapa dari pengurangan berat agregat halus yang digunakan pada kuat tekan umur 28 hari, serta telah dilakukan analisa prosentase peningkatan maupun penurunan yang disajikan dalam Tabel 3. 
Tabel 3. Prosentase Penurunan Kuat Tekan.

\begin{tabular}{ccccc}
\hline NO & $\begin{array}{c}\text { Kode } \\
\text { Benda } \\
\text { Uji }\end{array}$ & \multicolumn{2}{c}{ Kuat Tekan } & $\begin{array}{c}\text { Prosentase } \\
\text { Penurunan } \\
\text { \% }\end{array}$ \\
\hline $\mathbf{1}$ & $\mathrm{N}$ & 271,80 & 22,13 & - \\
\hline $\mathbf{2}$ & $5 \%$ & 205,12 & 16,70 & -24.53 \\
\hline $\mathbf{3}$ & $10 \%$ & 102,57 & 8,35 & -62.26 \\
\hline $\mathbf{4}$ & $15 \%$ & 76,92 & 6,26 & -71.70 \\
\hline $\mathbf{5}$ & $20 \%$ & 64,11 & 5,22 & -76.41 \\
\hline \multicolumn{5}{l}{ Sumber : Data Pengujian. }
\end{tabular}

Dari Tabel 3. diatas menunjukan bahwa prosentase penurunan kuat tekan benda uji paving block pada umur 28 hari dengan substitusi arang tempurung kelapa dari berat pasir yang digunakan mengalami penurunan kuat tekan. Dengan nilai beruntun dari benda uji, 5\%, $10 \%, 15 \%$, dan $20 \%$, adalah $-24,53 \%,-62,26 \%,-71,70 \%,-76,41 \%$.

\subsection{Penggolongan Mutu Paving block.}

Hasil analisa data penelitian selanjutnya digolongkan dalam standar mutu kuat tekan paving block dengan mengacu pada (SNI 03-0691-1996) Paving block.[1] Berikut adalah penggolongan mutu kuat tekan paving block.

Tabel 4. Penggolongan Mutu Paving block.

\begin{tabular}{cccc}
\hline No & $\begin{array}{c}\text { Kode } \\
\text { Benda Uji }\end{array}$ & $\begin{array}{c}\text { Kuat } \\
\text { Tekan } \\
\text { (Mpa) }\end{array}$ & $\begin{array}{c}\text { Mutu } \\
\text { Paving block }\end{array}$ \\
\hline 1 & $\mathrm{~N}$ & 22,13 & $\mathrm{~B}$ \\
\hline 2 & $5 \%$ & 16,70 & $\mathrm{~B}$ \\
\hline 3 & $15 \%$ & 8,35 & Tidak Memenuhi Standar \\
\hline 4 & $15 \%$ & 6,26 & Tidak Memenuhi Standar \\
\hline 5 & $20 \%$ & 5,22 & Tidak Memenuhi Standar \\
\hline
\end{tabular}

Sumber : Data Pengujian.

Dari Tabel 4. bisa kita lihat hasil dari konversi kuat tekan $\mathrm{kg} / \mathrm{cm}^{2} \mathrm{ke}$ Mpa sehingga didapat pengolongan mutu paving block, pada kode benda uji normal paving block tergolong dalam mutu kelas B, sedangkan pada kode benda uji 5\% tergolong dalam mutu kelas B, untuk kode benda uji 10\%, 15\% dan 20\% tidak memenuhi standar mutu paving block. 


\section{Kesimpulan dan Saran}

\subsection{Kesimpulan.}

Berdasarkan hasil pengujian dan pembahasan yang telah diuraikan sebelumnya maka dapat ditarik kesimpulan sebagai berikut :

1. Nilai kuat tekan masing - masing benda uji adalah; Normal sebesar $271,80 \mathrm{~kg} / \mathrm{cm}^{2}, 5 \%$ sebesar $205,12 \mathrm{~kg} / \mathrm{cm}^{2}, 10 \%$ sebesar $102,57 \mathrm{~kg} / \mathrm{cm}^{2}, 15 \%$ sebesar $76,92 \mathrm{~kg} / \mathrm{cm}^{2}$, dan $20 \%$ sebesar $64,11 \mathrm{~kg} / \mathrm{cm}^{2}$. Paving block dengan kode benda uji Normal tergolong dalam mutu kelas B dengan kuat tekan 271,80 kg/ $\mathrm{cm}^{2}$ (22,13 Mpa), kode benda uji 5\% dengan kuat tekan $205,12 \mathrm{~kg} / \mathrm{cm}^{2}$ (16.70 Mpa) tergolong dalam mutu kelas $\mathrm{B}$, sedangkan untuk paving block dengan tambahan arang kelapa 10\% - 20\% tidak tergolong dalam mutu standar kuat tekan paving block karena nilai kuat tekannya dibawah standar mutu kuat tekan paving block (SNI 03-0691-1996).

2. Paving block K-175 mengalami peningkatan serapan air dengan penambahan arang tempurung kelapa pada campuran paving block dengan prosentase arang kelapa sebesar $5 \%, 10 \%, 15 \%$, dan $20 \%$ dari berat pasir yang digunakan kesemuanya mengalami peningkatan penyerapan air dari rata-rata sebesar, 3,13 pada kode benda uji normal, 4,52 pada kode benda uji 5\%, 6,23 pada kode benda uji 10\%, 8,33 pada kode benda uji 15\%, 9,09 pada kode benda uji $20 \%$.

\subsection{Saran}

Perlu diadakan penelitian lebih lanjut mengenai proses pembuatan paving block karena dalam penelitian ini penulis masih banyak kekurangan-kekurangan dalam pembuatan benda uji paving block, terutama pada mix design dan prosentase agregat yang digantikan

1. Perlu diadakan penelitian lebih lanjut metode pembuatan paving block dengan mesin vibrasi atau mesin hidrolis agar pencetakan paving block lebih maksimal.

2. Perlu diadakan penelitian lebih lanjut dalam proses penumbukan atau pemadatan paving block dengan mengunakan cara manual. Karena dalam penelitian ini proses pemadatan atau penumbukan dengan alat tumbuk balok kayu dan plat besi. 


\section{Daftar Pustaka}

[1] Badan Standar Nasional Indonesia, "Bata Beton (Paving Block)," Sni 03-0691-1996, pp. 1-9, 1996.

[2] A. Salam and S. D. Hartantyo, "Pengaruh Penambahan Serat Pelepah Pisang Pada Pembuatan Paving Block K-175,” J. CIVILA, vol. 2, no. 2, p. 8, 2017.

[3] A. Purba, "PERBANDINGAN MUTU PAVING BLOCK," no. 1.

[4] A. C. Sembiring et al., "Uji Kuat Tekan Dan Serapan Air Pada Paving Block Dengan Bahan Pasir Kasar, Batu Kacang, Dan Pasir Halus,” vol. 1, no. 1, 2017.

[5] A. S. Agar-Ozbek, J. Weerheijm, E. Schlangen, and K. Van Breugel, "Investigating porous concrete with improved strength: Testing at different scales," Constr. Build. Mater., vol. 41, pp. 480-490, 2013.

[6] S. Y. Chung, T. S. Han, S. Y. Kim, and T. H. Lee, "Investigation of the permeability of porous concrete reconstructed using probabilistic description methods," Constr. Build. Mater., vol. 66, pp. 760-770, 2014.

[7] G. Yanti, Z. Zainuri, and S. W. Megasari, "Analisa Perbandingan Penambahan Variasi Consol Terhadap Kuat Tekan Beton," SIKLUS J. Tek. Sipil, vol. 4, no. 1, pp. 59-66, 2018.

[8] M. A. R. Bhutta, K. Tsuruta, and J. Mirza, "Evaluation of high-performance porous concrete properties," Constr. Build. Mater., vol. 31, pp. 67-73, 2012.

[9] R. R. Dhana et al., "Fly ash tempurung kelapa sebagai bahan tambah pada beton non struktural," vol. 5, no. 2, pp. 121-127, 2019.

[10] A. R. Mukhlis Iwan Mustaqim, Juli Marliansyah, "Pengaruh Penambahan Abu Tempurung Kelapa Terhadap Kuat Tekan Paving Block,” J. Mhs. Tek., vol. 3, pp. 1-9, 2017.

[11] E. Gardjito, A. I. Candra, and Y. Cahyo, "Pengaruh Penambahan Batu Karang Sebagai Substitusi Agregat Halus Dalampembuatan Paving Block," UKaRsT, vol. 2, no. 1, p. 36, 2018.

[12] J. Pcc, "Pengisi Dalam Proses Pembuatan Paving Dengan Semen,” vol. 1, no. 2, pp. 8$16,2012$. 
[13] S. Maliar, D. Jurusan, T. Sipil, M. Jurusan, and T. Sipil, "Jurnal Momentum ISSN : 1693-752X PENGARUH PENGGUNAAN FLY ASH SEBAGAI PENGGANTI AGREGAT TERHADAP," vol. 17, no. 1, pp. 42-49, 2015.

[14] A. Artiyani, “Abu Sampah Sebagai Bahan Paving Block Anis Artiyani,” pp. 1-11.

[15] SNI 03-2834-2000, "Tata Cara Pembuatan Rencana Campuran Beton Normal. SNI 032834-2000,” Badan Stand. Nas., pp. 1-34, 2000.

[16] C. R. Gagg, "Cement and concrete as an engineering material: An historic appraisal and case study analysis," Eng. Fail. Anal., vol. 40, pp. 114-140, 2014.

[17] J. Kaufmann, "Evaluation of the combination of desert sand and calcium sulfoaluminate cement for the production of concrete," Constr. Build. Mater., vol. 243, p. 118281, 2020 .

[18] T. Shane and R. Steffes, Vibration study for consolidation of portland cement, no. 970499. 1999.

[19] J. T. Sipil and P. N. Jakarta, “Tekban,” 2005.

[20] B. Ramesh, V. Gokulnath, and M. Ranjith Kumar, "Detailed study on flexural strength of polypropylene fiber reinforced self-compacting concrete," Mater. Today Proc., no. xxxx, 2019.

[21] N. Wariyatno and Y. Haryanto, "Kuat Tekan Dan Kuat Tarik Belah Sebagai Nilai Estimasi Kekuatan Sisa Pada Beton Serat Kasa Aluminiumakibat Variasi Suhu,” Din. Rekayasa, vol. 9, no. 1, pp. 21-28, 2013.

[22] SNI 03-6805-2002, "Metode Pengujian untuk Mengukur Nilai Kuat Tekan Beton Pada Umur Awal dan Memproyeksikan Kekuatan Pada Umur Berikutnya," Badan Standardisasi Nasional. 2002.

[23] A. I. Candra, E. Gardjito, Y. Cahyo, and G. A. Prasetyo, "Pemanfaatan Limbah Puntung Rokok Filter Sebagai Bahan Campuran Beton Ringan Berpori," UKaRsT, vol. 3, no. 1, p. 82, 2019. 